\title{
Instructions for Authors
}

\section{Submission of the First Version of the Manuscript}

We would like to invite researchers in the field of humanities to publish their works in MANUSYA. A prospective contributor should submit to the Editor-inChief an electronic copy and two hard copies of his/her paper including two abstracts, one in English and another in Thai. The length of the paper should not exceed 20 pages. It should be printed on one side of $A_{4}$ paper in single spacing with Times New Roman 12. The author should follow the style guide below regarding the citation and reference system.

Any paper written by a non-native speaker of English must be checked by a native speaker for its grammaticality before submission. All submitted papers will be reviewed by the issue editor and two readers or reviewers. Within three months the author will receive a letter informing whether his/her paper is accepted or rejected.

\section{Submission of the Revised Version (Second Version)}

The author revises his/her paper according to the reviewers' comments, and submits it in the same format as the first version along with a one-page summary of the corrections via email to the Editor-in-Chief.

\section{3}

\section{Submission of the Corrected Version (Third Version)}

The revised paper is edited for the writing style by the language editor. After that, the author makes linguistic and stylistic corrections according to the language editor's suggestions and formats it according to the style guide below. 


\section{$4 \quad$ Submission of the Proofread Version (Final Version)}

Before all the edited manuscripts are submitted to the printing house, they are sent to the authors to proofread. After the authors have proofread their papers, they send them to MANUSYA as the final version.

\section{$5 \quad$ Style Guide for the First Version of the Manuscript}

In preparing the first version of their papers, all the authors are requested to observe the following style guide.

\subsection{Heading}

Headings should not be numbered and should be left-aligned.

\section{2 $\quad$ Foreign Words}

Foreign words cited as examples or key concepts may be written in scripts of each particular language, but they must be accompanied by the same words in phonetic alphabet or Romanized forms followed by glosses and translations of the whole phrase or sentence. All the cited foreign words should be in italics. The author should avoid mixing unnecessary non-English words as if they were English words in sentences unless they are commonly accepted as English loanwords.

\subsection{Quotation Marks}

Use double quotation marks for direct quotation and single quotation marks for glosses (translations of foreign words).

\subsection{Footnotes}

Use the footnote command to insert all footnotes automatically. Do not use endnotes. Footnotes are used only for adding useful information, not for references.

\subsection{Citation and Reference System}

Full bibliographical information of literature cited in the papers should be given in the list of references at the end of the paper. Within the text, only brief author-date citations should be made, giving the author's surname, year of publication and page number(s) where relevant. The use of footnotes to indicate citations will not be accepted. Examples showing the system of citation in MANUSYA are as follows. 
- According to Matisoff (1991:90) ...

- Matisoff (1991: 90) argued that ...

- ... (see also Comrie 1989:34-39)

Do not cite a person by just placing the surname + year at the end of a sentence or a paragraph without indicating clearly which part of the content is cited.

\subsection{References at the End}

The following are examples of references placed at the end of a paper. Note that the first line should be hanging. Do not use multiple spaces or tabs in a reference entry.

Chambers, J.K. and Peter Trudgill. 1980. Dialectology. Cambridge: Cambridge University Press.

Comrie, Bernard. 1989. Language Universals and Linguistic Typology. 2nd edition. Chicago: University of Chicago Press.

Dane, Gabrielle. 1998. Reading Ophelia's Madness. Examplaria 10.2 (1998). June 22, $2002<\mathrm{http} / / /$ web.english.ufl.edu/english/exemplaria/danefram.htm>.

Fishman Joshua. A. (ed.). 1968. Reading in the Sociology of Language. The Hague: Mouton.

Hoonchamlong, Yuphaphann. 1991. Some Issues in Thai Anaphora: A Government and Binding Approach. Doctoral dissertation, University of Winconsin, Madison.

Luo, Yongxian. 1994. Tonal Irregularities in Thai Revised. Paper presented at the 27th International Conferences on Sino-Tibetan Languages and Linguistics, 12-16 October, 1994, Paris.

Matisoff, James A. 1991. Endangered Languages of Mainland Southeast Asia. In Endangered Languages, edited by Robert H. Robins and Eugenius M. Uhlenbeck, pp. 189-288. Oxford: Berg.

Ross, Malcolm D. 1992. The Sound of Proto-Austronesian: An Outsider's View of the Formosan Evidences. Oceanic Linguistics 31.1: 23-64.

Starobinski, Jean. 1979. Words upon words: the anagrams of Ferdinand de Saussure, translated by Olivia Emmet. New Haven, Conn.: Yale University Press.

Victorian Women Writers Project, edited by Perry Willett. May 200o, Indiana University. June 26, $2002<$ http://www.indiana.edu/ letrs/vwwp/>.

All kinds of figures should be inserted in appropriate positions in the text, but also provided as separate files in an image format, or Excel: for charts. Excel 
files should be saved as PDF too. Photographs must be scanned to PDF high resolution or in image format. Sources of the figures and tables taken from other works must be indicated. Also, in case the author has the original file of any photograph he/she should attach it with the submitted paper.

\section{$7 \quad$ Style Guide for the Final Version of the Manuscript}

In preparing the third version of their papers, all the authors are requested to observe the following style guide in addition to what has been done for the first version.

\subsection{Margins}

\begin{tabular}{llll}
\hline Top: & $\mathbf{1 . 7 5}$ & inches & or $4.44 \mathrm{~cm}$. \\
\hline Bottom: & 1.75 & inches & or $4.44 \mathrm{~cm}$. \\
Left: & 1.5 & inches & or $3.81 \mathrm{~cm}$. \\
Right: & 1 & inch & or $2.54 \mathrm{~cm}$. \\
\hline
\end{tabular}

\subsection{Text Layout and Character Formats}

The text should preferably be prepared on Microsoft Word for Windows and set in Times New Roman.

Editor-in-Chief

MANUSYA:Journal of Humanities

Faculty of Arts

Chulalongkorn University

Bangkok 10330

Thailand

Telephone: (662) 218-4663

E-mail:manusyajournal@gmail.com

Website: http://www.manusya.journals.chula.ac.th 